\title{
PESQUISA EM SERES HUMANOS: PERSPECTIVAS ATUAIS NO BRASIL
}

\author{
RESEARCH IN HUMANS: CURRENT PERSPECTIVES IN BRAZIL
}

\author{
${ }^{1}$ Célia Alcantara Cunha Lima
}

\section{RESUMO}

Neste trabalho abordou-se a normatização da ética na experimentação em seres humanos no Brasil, operacionalizada pela Comissão Nacional de Ética em Pesquisa (CONEP) do Conselho Nacional de Saúde (CNS). Analisaram-se princípios internacionais da Bioética como referencial teórico para a regulamentação brasileira. Foram revisadas publicações nacionais e internacionais, via Portal Periódicos Capes, relativas a infrações éticas históricas, como reflexão para os dias atuais. Analisou-se o Projeto de Lei (PL) $200 / 2015$ do Senado Federal, que propõe flexibilizações na regulamentação brasileira. Concluiu-se que as modificações pretendidas deverão ser discutidas em profundidade por bioeticistas, cientistas e juristas brasileiros com discussão estendida à sociedade.

Palavras-chave: Bioética, Experimentos em humanos, Regulamentação

\begin{abstract}
This work addressed the norms of ethics for human experimentation in Brazil, operationalized by the National Research Ethics Commission (CONEP) of the National Health Council (CNS). It analyzed international principles of bioethics as a theoretical framework for the Brazilian regulation. National and international publications were reviewed, by Capes periodicals, relating to historical ethical infractions, such as reflection to the current day. It analyzed the law (PL) 200/2015 of the Senate, which proposes flexibilities in Brazilian legislation and concluded that the requested changes should be discussed in depth by bioethicists, scientists and Brazilian lawyers with extended discussion to society.
\end{abstract}

Keywords: Bioethics, Human experiments, Regulation

\footnotetext{
${ }^{1}$ Doutora em Ciências Odontológicas pela São Leopoldo Mandic, CPO SLMANDIC (Brasil). Coordenadora do Centro Universitário Fluminense - UNIFLU, Goitacazes - RJ (Brasil). E-mail: c.alima@bol.com.br
} 


\section{INTRODUÇÃO}

A relevância da ética na experimentação em seres humanos é consensual. Em tese, ninguém há que ache natural o sacrifício do ser humano e a banalização da vida. Entretanto, intercorrências negativas têm ocorrido na história da pesquisa científica por fatores corporativos e econômicos, dentre outros. O pensar ético, possível pela formação individual do pesquisador não exclui a necessidade da adoção de normativas, haja vista a complexidade e amplitude conceitual da ética.

A adoção de princípios bioéticos na investigação científica vai além da relação pesquisador sujeito da pesquisa. Interessa à sociedade como um todo. Inclui igualmente discussões relativas às agências de fomento, à regulação da indústria farmacêutica e também à academia, pois onde se iniciam os trabalhos de pesquisa, ou seja, na iniciação científica, deve também ser estimulada a conscientização da ética pelo futuro pesquisador. Neste aspecto, a bioética pode estar dependente de aprendizado. Sua importância na delimitação quanto à amplitude da ação na experimentação ou na intervenção clínica deve ser enfatizada ainda na vida acadêmica, em todos os cursos das áreas que lidam com o ser humano nos diversos aspectos da vida e não somente nos cursos da área da saúde. A missão da universidade, apoiada no tripé ensino pesquisa e extensão igualmente equiparadas e indissociadas (CF 1988) exige modificações na atividade e no pensamento acadêmicos (ANDRADE \& SILVA, 2009). A atividade de iniciação científica torna-se um campo propício ao ensino das práticas saudáveis em pesquisa. A concepção de uma nova formação acadêmica, que inclua a pesquisa e a extensão requer preparo para estas atividades como caminho para tomadas de decisões seguras para o ser humano e para a sociedade.

O efeito de um tratamento sobre o homem só pode ser observado no próprio homem (VIEIRA \& HOSSNE, 2010), entretanto os experimentos em humanos serão admissíveis quando o risco se justificar pelo benefício (CNS, 2012). Esta experimentação deve representar a última etapa de uma sequência, e ser precedida por experimentação laboratorial e por testes em animais. Importante refletir que a ausência de danos em animais não garantiriam ampla segurança para humanos (HOSSNE \&VIEIRA, 1995; Res CNS 196/96; Res CNS 466/2012). Desta forma, não se poderá prescindir da experimentação no homem. O cuidado científico, refletido no rigoroso delineamento da pesquisa, deverá ser obedecido em qualquer tipo de pesquisa (SARDENBERG, 1999). "Experimentos são necessários para que a 
ciência caminhe, entretanto, há questões éticas que não dizem respeito só à ciência" (VIEIRA \& HOSSNE, 2010).

A Res. CNS 196/96, atualizada pela Res CNS 466/12, prevê diretrizes éticas para a experimentação em seres humanos no Brasil, dispondo sobre a proteção devida aos participantes de pesquisa quanto ao respeito à sua dignidade individual ou coletiva, de forma direta ou indireta e incluindo o manejo de seus dados, informações ou material biológico.

Fundamenta-se em recomendações universais como o Código de Nuremberg (1947), a Declaração Universal dos Direito Humanos (1948), e a Declaração de Helsinque (1964) e suas versões de 1975, 1983, 1989, 1996 e 2000, o Pacto Internacional sobre os Direitos Econômicos, Sociais e Culturais, (1966); o Pacto Internacional sobre os Direitos Civis e Políticos (1966); a Declaração Universal sobre o Genoma Humano e os Direitos Humanos, (1997); a Declaração Internacional sobre os Dados Genéticos Humanos, (2003) a Declaração Universal sobre Bioética e Direitos Humanos, (2004); e a Declaração Nacional de Bioética e Direitos Humanos (2005). Incorpora Incorpora [...] os referenciais de bioética, autonomia, não maleficência, beneficência, justiça e equidade dentre outros, e visa assegurar os direitos e deveres dos participantes de pesquisa, à comunidade científica e ao Estado".

O planejamento de uma pesquisa experimental em humanos deverá ser detalhado num projeto, onde são estabelecidos os objetivos e descrita a metodologia a ser utilizada. Um desenho bem delineado, conforme preconiza a Declaração de Helsinque (2000). Os participantes, ou sujeitos da pesquisa, deverão ser informados sobre sua participação no experimento. Muito se tem considerado sobre a suficiência do termo de consentimento livre e esclarecido (TCLE) no âmbito do Direito Civil quanto ao princípio da autonomia (Garib, 2015), o que, entretanto, foge ao enfoque deste estudo. Muito cuidadosa e claramente, os participantes devem receber explicações sobre a pesquisa. É absolutamente necessária a compreensão dos riscos a que eventualmente possam estar expostos, se usarão medicamentos, se sofrerão intervenções cirúrgicas, se estarão expostos à radiações, dentre outros, e devem manifestar seu livre consentimento, respeitando-se as limitações legais. Também não poderão sofrer constrangimentos ou ter seus direitos cerceados (Res CNS 466/12).

Segundo Vieira \& Hossne (2011) "a experimentação com seres humanos causa impacto porque as pessoas temem o abuso". Se o objetivo da pesquisa é melhorar a saúde e o bem-estar dos pacientes, nunca se pode causar danos ou submetê-los a graves riscos para obter esses objetivos (SUSSMAN, 1998). 
Pesquisar é procurar. Pesquisa científica é a busca metodologicamente organizada dentro da ciência e nas diversas áreas do conhecimento humano. Pressupõe observação com testes de reprodutibilidade e confiabilidade, intervenções, interpretação e divulgação de resultados. Exige parâmetros bem delineados quanto ao método científico, sendo imprescindível que se observe a ética em todas as suas etapas, culminando no respeito ao sujeito da pesquisa, seja ser humano ou animal.

"A ciência não é de valor supremo, de modo que todas as outras escalas de valores devam estar a ela subordinada (Pio XII, 1952 apud Beecher, 1966)”. É necessário o equilíbrio entre a investigação científica e o respeito aos valores da vida e da dignidade humanas, dentre outros.

\section{REVISÃO DA LITERATURA / DISCUSSÃO}

\subsection{Infrações Éticas na História}

$\mathrm{O}$ respeito à dignidade humana inclui o respeito ao ser humano participante de investigação científica (VIEIRA \& HOSSNE, 2006; CNS 2012; OBANDO, 2015). É uma vida a serviço de uma investigação. A história mostrou o quanto, nos experimentos científicos, subestimou--se a dignidade humana, e como, no afã de novas descobertas que visavam a preservação da vida, descumpriram-se princípios básicos de preservação da própria vida. Relembrar exemplos históricos de infração ética em pesquisa oferece subsídios para a reflexão e aprimoramento da avaliação da conduta ética na atividade experimental contemporânea. A procura pelo conhecimento científico e os interesses econômicos nunca poderão subestimar a inviolabilidade do ser humano.

A discussão atual sobre a ética aplicada à pesquisa em humanos é multidisciplinar, e “inclui filósofos, teólogos, advogados, sociólogos pessoas da sociedade, tanto o cidadão comum como os usuários do Sistema Único de Saúde (SUS) enquanto participantes de pesquisa científica" (PALÁCIOS et al., 2010). Interessa também aos "profissionais da educação, do direito, da sociologia, da economia, da teologia, da psicologia (JUNQUEIRA, 2008). Médicos, cirurgiões-dentistas, psicólogos e demais profissionais que lidam com seres humanos em todos os aspectos de vida, e não apenas o aspecto saúde deverão ter formação acadêmica na bioética, como forma de aprimoramento do discernimento das diversas facetas de que se reveste a condução de pesquisa em seres humanos, e desta forma tendo condições 
de estender esses conhecimentos também às suas atividades clínicas e demais atendimentos profissionais prestados ao ser humano, diretamente ou por meio de manipulação de seus dados.

A vida é breve, a ciência é duradoura, a oportunidade é ardilosa, a experimentação é perigosa, o julgamento é difícil (Hipócrates 460-377 a C). Desde épocas remotas, médicos experimentavam no próprio doente novas terapias na busca da cura. Katz (2005) afirma que,

no alvorecer da ciência médica, em meados da década de 1850 , a pesquisa assumiu uma dimensão não contemplada por Hipócrates. Pela primeira vez, a experimentação se estenderia até incontáveis pacientes, não para seu benefício direto, mas o avanço do conhecimento científico para o benefício de humanidade. A Medicina agora realizaria a promessa de reverter o aforismo de Hipócrates: A vida seria mais longa, a arte da cura mais rápida, o julgamento mais fácil. Para alcançar estes objetivos, uma nova geração de médicos pesquisadores incentivava seus pacientes a fazer sacrifícios em nome da ciência médica. Assim, a experimentação tornou-se ainda mais traiçoeira.

O caso Neisser passou a ser citado dentre os episódios marcantes de infração ética. Dr. Albert Neisser (1900) eminente cientista que teve papel relevante no diagnóstico diferencial entre a sífilis e a gonorréa,, foi autor do mais abrangente trabalho experimental sobre sífilis publicado na história (LIGON 2005). A metodologia adotada por ele, entretanto, é citada como infração à bioética. Relata Ligon (2005):

Em 1892, injetou, via subcutânea, soro de um paciente em estágios precoces de sífilis em quatro pacientes do gênero feminino com idade entre 10 a 24 anos... . A seguir, injetou por via endovenosa $30 \mathrm{ml}$ de amostras de soro de pacientes em várias fases da sífilis em quatro pacientes do gênero feminino, prostitutas, com idade de 17 a 20 anos de idade. Todas desenvolveram sífilis.

Estava convencido, entretanto de haver trabalhado corretamente e nem sua licença nem sua posição acadêmica foram afetadas (Jatz, 2005) tendo apenas pago uma multa FRESQUET, 2013).

Pesquisas científicas realizadas durante a segunda guerra mundial foram consideradas posteriormente crimes de guerra e crimes contra a humanidade (LAWRENCE (1996). O julgamento dos envolvidos ocorreu em Nuremberg, então zona de ocupação dos americanos, no que ficou conhecido como o Julgamento dos médicos (novembro de 1945 a outubro de 1946). Interpretado como reação internacional às desumanidades na pesquisa experimental, como "crise de consciência" (Garrafa \& Prado, 2007), na comunidade científica, no sentido de assegurar a integridade e dignidade das pessoas, aí incluindo participações em pesquisa biomédica, trouxe como legado para a ciência 10 princípios 
básicos de permissão governamental para a preservação da dignidade e integridade do ser humano. "O Código de Nuremberg, que recebeu contribuição substancial de dois médicos americanos, Leo Alexander e Andrew Ivy, foi uma tentativa de preencher a lacuna representada pela relativa ausência de declarações formais de ética na experimentação em humanos" (CHILDERSS, 2000). Relataram-se experimentos com congelamento (Childerss, 2000; Jatz, 2005), contaminação por malária e gás mostarda e grandes altitudes (JATZ, 2005). Os experimentos com congelamento teriam a presumível finalidade de observar o tempo de resistência do ser humano a esta condição, isto e, durante quanto tempo resistiriam soldados quando aviões fossem abatidos e caíssem no mar.

Dentre os princípios do Código de Nuremberg estão o consentimento voluntário, que o projeto contemple resultados proveitosos para a sociedade, que não poderiam ser obtidos por outros métodos. Há também recomendação de experimentação prévia em animais e recomendações para evitar-se sofrimento físico, mental e lesões graves. Prevista a adequação entre o risco e o benefício, que existam instalações adequadas para o experimento, que estes sejam conduzidas por cientista qualificado, que, observados efeitos adversos, deveria encerrar a pesquisa.

"No período nazista a morte de seres humanos fazia parte do projeto de pesquisa" (JATZ, 2005) e da mesma forma as sequelas incapacitantes. Apesar de graves violações aos direitos individuais muitos médicos passaram a ter carreiras de sucesso, e em muitos casos foram homenageados (JATZ, 2005; FRESQUET, 2013). Seidelman (1985) afirmou que os experimentos de Mengele representaram a aplicação do que foi considerado pesquisa científica legítima na área da engenharia genética humana, tendo tido início na Inglaterra, praticada nos Estados Unidos e no Canadá, fora da Alemanha e antes da eclosão da guerra.

O estudo sobre ciclo da sífilis não tratada conduzido pelo United States of Public Health, o Projeto Tuskegee foi outro fato marcante de infração à bioética. É relatado como um estudo longitudinal de 42 anos e que veio a público em 1972. Estudou-se a evolução da doença sem tratamento em 399 homens negros adultos, e um grupo controle de 201 homens sadios. Relata Solomon (1985) que os doentes eram desencorajados ou até mesmo impedidos de procurar tratamento fora do programa. Sendo a sífilis tratada desde sendo tratada desde 1943 pela penicilina (Avelleira \& Bottino, 2006), o que teria motivado a negativa de tratamento? O que estaria como primeiro plano, a cura do ser humano ou os conhecimentos científicos advindos da observação da terrível evolução da doença e da necropsia em seus corpos? 
$\mathrm{Na}$ área de Odontologia, em experimento sobre a rotação mandibular durante o crescimento craniofacial realizado por Björk (1969) na Dinamarca, num estudo longitudinal, foram implantadas agulhas nas mandíbulas de 100 adolescentes, que fizeram radiografias craniofaciais (telerradiografias) dos 12 aos 24 anos. Não foi considerado o efeito estocagem da radiação X, para essas exposições repetidas à qual os adolescentes foram expostos e esta é uma questão de difícil correlação da exposição à radiação e o eventual posterior aparecimento de neoplasias, haja vista não se tratar de um efeito imediato.

\subsection{A Regulação na Pesquisa com seres Humanos}

A percepção pessoal da ética individual ou coletiva é em parte, pautada pelo multiculturalismo, daí a aceitação ou o repúdio a determinados atos dependerem em parte do contexto social. Regulamentações são necessárias porque padrões internacionais minimizam as influências culturais de países e de segmentos profissionais, e a participação multidisciplinar nas discussões e na análise de projetos de pesquisa é conveniente e enriquecedora. Garrafa 2007) *** afirma que "para a bioética laica, o que é bom, certo ou justo para uma comunidade moral, pode não ser para outra, já que suas moralidades, ou costumes, podem ser diversos".

Van Rensselaer Potter (1970), é considerado o pioneiro a usar o termo "bioética" como normas de abordagem dos problemas da ciência aplicada ao ser humano, tendo estendido posteriormente este conceito para além do aspecto biomédico, conferindo enfoque multidisciplinar à bioética, o que chamou de bioética global (HATE, 2009). Antes, em 1927 o termo foi utilizado por Fritz Jahr (1927) numa abordagem diversa, conforme relata SCHRAMM ( 2011). Potter (1971) ocupou-se de analisar a condição do ser humanos diante da investigação científica e dos avanços biotecnológicos, tendo afirmado que "o conceito de bioética funcionaria como forma de enfatizar os dois componentes absolutamente necessários: conhecimento biológico e valores humanos."

Garrafa \& Prado (2009) ressaltaram a importância conferida à Declaração de Helsinque pela revistas científicas mundiais, que se nela se baseiam para instruções aos autores.

O Código de Nuremberg (1947), a Declaração Universal dos Direitos Humanos (1948) e a Declaração de Helsinque (1964) foram marcos importantes para a regulamentação da pesquisa com seres humanos. O estudo de Henry Beecher (1966) representou uma importante reflexão sobre a incorporação destes princípios à prática da pesquisa clínica nos Estados 
Unidos, e incluiu o apelo para a obtenção do consentimento informado. Afirmam Harkness et al. (2001) que "Beecher representou não apenas regulamentação mas também contribuiu para o desenvolvimento da percepção, pelo pesquisador, das questões éticas”. Regulamentação é insuficiente diante de uma percepção pessoal equivocada ou tendenciosa. Humberto Eco (2016), afirmou que "Hitler matou seis milhões de judeus levando a sério o antigo Protocolo dos Sábios de Sião. É natural que toda forma de crime na história nasça da desinformação orientada", afirmou. Assim, pode-se compreender a importância tanto da regulamentação quanto da construção pessoal ética em pesquisas com seres humanos.

\title{
2.3 A Regulação Ética Atual no Brasil
}

O marco regulatório de pesquisas em seres humanos no Brasil é exercido pela CONEP (DINIZ, 2008). Supervisionando os CEPs, formam o sistema CEP/CONEP, que tem efetuado um trabalho de inestimável valor na pesquisa em seres humanos nas diversas áreas de conhecimento. Palácios \& Rego (2015) consideram que

\begin{abstract}
Nosso sistema de avaliação ética de pesquisas é admirado por pesquisadores e acadêmicos dos mais variados países exatamente por ser um sistema e não um conjunto de comitês que atuam isoladamente. É admirado por estar vinculado a um sistema independente de controle social e contar com a participação democrática de pesquisadores, órgãos reguladores, participantes de pesquisas, universidades e serviços de saúde. A dinâmica do funcionamento do sistema está em contínuo aperfeiçoamento, como não poderia deixar de ser. Recentemente, por exemplo, foi revista a regulamentação básica que trata das normas e princípios gerais para a realização de pesquisas em todas as áreas, coroada por uma consulta pública na qual os diversos atores participaram e influíram.
\end{abstract}

Sólido, ágil e transparente, atualmente via Plataforma Brasil, que permite o cadastramento on line dos projetos de pesquisa, consultas e acompanhamento destes pelos pesquisadores e pelo público. A distribuição para análise pelos CEPs, têm o prazo de 30 dias a partir da aceitação do projeto, e a checagem documental deverá ser realizada em até 10 dias após a submissão do projeto de pesquisa (CNS Norma Operacional 001/2013). Desta forma o sistema CEP CONEP é extremamente rápido e objetivo na avaliação de projetos de pesquisa. Dilatação neste prazo pode ocorrer, no atendimento a eventuais pendências.

A autonomia limitada de pacientes psiquiátricos, idosos, crianças, a deficiência de escolaridade e pobreza pode favorecer a aquiescência benévola por parte dessas pessoas para participação em pesquisas clínicas. Essas participações requerem que o consentimento livre e esclarecido seja mais abrangente. São pessoas consideradas como "com substancial diminuição de sua capacidade de decisão” (RES CNS 466/2012). A abrangência do 
consentimento para além da decisão pessoal, ocasionada pela condição de vulnerabilidade desses participantes de pesquisa, requer "justificativa clara de sua escolha, especificada no protocolo e aprovada pelo CEP e pela CONEP, juntando-se a aquiescência dos representantes legais". Também são considerados vulneráveis os membros de corporações, indígenas, presidiários e todas as pessoas passíveis de sofrer represálias pelo não consentimento ao experimento para o qual tenha sido convidado. Tudo em nome da ciência é um axioma relativo quanto à ética na pesquisa. É necessária a decisão pessoal pautada no esclarecimento de eventuais riscos a que se possa estar exposto e o respeito dos limites legais para a participação.

A Lei $n^{\circ} 11.105$, 24 de março de 2005, Lei de Biossegurança, foi objeto de discussão quanto à constitucionalidade das pesquisas com células-tronco obtidas de embriões humanos obtidas por fertilização in vitro no Supremo Tribunal Federal (STF) em 2008. O sistema CEP-CONEP foi mencionado pelo Ministro Eros Grau em seu voto como requisito para a adoção de pesquisa e terapia com células-tronco embrionárias obtidas de fertilização in vitro citando que "deverão ser empreendidas unicamente se previamente autorizadas por comitê de ética em pesquisa do Ministério da Saúde (não apenas das próprias instituições de pesquisa e serviços de saúde)". O uso destas células com finalidades terapêuticas foi considerado constitucional. Em justificativa ao seu voto o Ministro César Peluso (2008) afirmou que "o problema das células-tronco embrionárias é tão sério que não pode ficar nas mãos dos cientistas". A questão das células-tronco, dos embriões congelados, da produção de novos fármacos, o desenvolvimento de novos protocolos cirúrgicos, além de outros, devem sempre passar pela análise ética multidisciplinar e não podem sofrer avaliação unilateral por um único poder ou ser analisado dentro de uma única área do conhecimento humano ou segmento profissional.

O sistema de avaliação de projetos de pesquisa CONEP/CEP tem sido interpretado por alguns segmentos como de excessiva rigidez. Transcrevemos parcialmente o pronunciamento do Sr. Gabriel Tannus, presidente da Interfarma, em evento de iniciativa da Sociedade Brasileira de Medicina Farmacêutica de Pesquisa, quando apresentou dados de cerca de 30 indústrias farmacêuticas que estariam no Brasil, quanto ao aspecto pesquisa clínica. Relatam Aligiere \& Tannus (2004)

Havia, em 2000, nos Estados Unidos, 46 mil médicos envolvidos em pesquisa clínica. Na mesma época três mil participavam de protocolos na América Latina. Essa diferença, devido ao passado do trabalho de pesquisa no Brasil, que não lhe conferiu credibilidade internacional, vem caindo progressivamente [...]. Um grande 
passo foi dado em 1996, com a criação dos Conselhos de Ética em Pesquisas (CEP), conquista de espaço no mundo científico e de respeito por nossos pesquisadores e seus trabalhos [...]. O tempo para aprovação das pesquisas clínicas ainda é muito longo e o planejamento das pesquisas obedece a cronogramas rígidos, que não permitem atrasos em sua implementação [...]. É preciso que se encontrem caminhos junto aos órgãos oficiais (CEPs, a CONEP e ANVISA), que possibilitem redução desse prazo de aprovação. A adequada integração indústriauniversidade-governo pode e deve contribuir decisivamente para tornar o Brasil mais competitivo. As indústrias vêm trabalhando no sentido se tentar acelerar esse tempo, sem prejuízo da ética e da legislação.

Afirmam Zanneti \& Tannous que "o Senado brasileiro acredita dar sua contribuição ao avanço das pesquisas clínicas no Brasil ao encampar proposta de empresários representados pela Aliança Pesquisa Clínica Brasil e pela Interfarma (Associação da Indústria Farmacêutica de Pesquisa)" que estaria expressa no PL n 200 /2015. Palácios \& Rego (2015) opinam não se tratar de um "projeto que manifeste preocupação com as pesquisas científicas no país e sim com ensaios clínicos de produtos para a saúde que possam entrar no mercado brasileiro e estaria direcionado aos interesses da indústria farmacêutica".

Harkness et al. (2001) afirmam que "a experimentação em humanos tem sido marcada por controvérsias geradas pela pesquisa efetuada em países em desenvolvimento por cientista de países industrializados, quando procuram fugir dos rigorosos padrões éticos de seus países".

Seria então duas abordagens éticas para um mesmo problema, uma adequação perigosa e desumana.

O PL do Senado Federal n 200 / 2015 (Comissão: CCT, relatoria do senador Aloysio Nunes Ferreira) prevê mudanças significativas na regulamentação vigente. Este projeto demanda cautela pela comunidade científica, devido à conotação moral que permeia esta questão e às vulnerabilidades próprias dos países em desenvolvimento com relação às flexibilizações dos princípios da bioética. Muitas vezes revestidas de apoio ao avanço científico-tecnológico são, numa análise mais acurada, atalhos procurados por grandes corporações, pela maior facilidade de adequações das regras mais rígidas dos países desenvolvidos num país que dá seus primeiros passos na normatização dessa questão, como o Brasil.

O sistema CONEP CEP do CNS tem como objetivo proteger os participantes de pesquisa no Brasil e assegurar que sejam preservados seus direitos. Vem desenvolvendo e aperfeiçoando este trabalho por duas décadas e está ameaçado de extinção pelo referido PL, que prevê, dentre outras alterações que a regulação da ética em pesquisa em seres humanos passe a ser da Agência Nacional de Vigilância Sanitária (ANVISA). Seria retirada a 
análise de projetos de pesquisa dos CEPs, subordinados à CONEP e cujos membros são acadêmicos, cientistas e representantes de usuários e seria delegada a tarefa a um colegiado não ligado diretamente à atividade de pesquisa, muito mais suscetível a influências políticas, se não pela intenção deliberada, mas sobretudo pelo desconhecimento da história da experimentação em humanos.

Há também que se refletir sobre o questionável preparo do Senado Federal como colegiado precipuamente habilitado para propor modificações na normatização da ética em pesquisa brasileira. Fortalecer a comunidade acadêmica e a sociedade com reflexões sobre o tema aprimoraria a crítica e propiciaria o aperfeiçoamento da proteção ao participante de pesquisa no Brasil, evitando-se eventuais retrocessos.

A reavaliação da regulamentação da ética na pesquisa por um colegiado leigo é preocupante.

Visões corporativas nacionais e internacionais estariam influenciando decisões importantes, senão vitais para o ser humano e para a sociedade brasileira. Quando leigos avaliam questões tão intricadas, difíceis até para acadêmicos, fica-se realmente à mercê de decisões que representariam retrocesso e não avanço. O Senado Federal naturalmente pretende o bem social e o avanço do Brasil no campo das ciências, porém não se pode analisar na ponta uma questão de tanta complexidade. Esta reflexão é profunda e deve ser ampla. Sem a participação maciça dos cientistas brasileiros e da academia, dificilmente será bem resolvida.

\section{CONCLUSÕES}

O protocolo ético para experimentação em seres humanos possui diversos requisitos. "Dois são mais importantes que os outros, e o primeiro é o consentimento informado, por razões morais, sociológicas e legais" afirma Beecher (1966). Deverá estar assinado pelo participante da pesquisa, quando capaz, e ou por seu representante legal. "Em segundo lugar, estariam qualificações pessoais do próprio pesquisador, informado, responsável e compassivo", conclui. Compaixão é um requisito fundamental, e resolveria muitas das questões associadas à relação pesquisador participante de pesquisa. Colocar-se no lugar do outro, respeitar sua vulnerabilidade, estar agradecido por sua boa vontade em participar da 
investigação, é um requisito de difícil normatização, por sua conotação moral de formação pessoal.

Por melhor que se explique e a despeito do que se escreva no termo de consentimento livre esclarecido, dificilmente, e eu me arriscaria a dizer que nunca, o participante de pesquisa saberia avaliar o risco eventual da pesquisa para sua saúde ou para sua vida. Para se compreender algumas situações são necessários conhecimentos prévios, que naturalmente ele não teria. Neste contexto, e como elo, entraria a compaixão do pesquisador, explicando amigavelmente, senão amorosamente e sem tendenciosidade esses riscos e sabendo interpretar medos, interrogações e ou eventual desistência do participante.

Geralmente o pesquisador se depara com a extrema boa vontade dos participantes de pesquisa em atendimento ambulatorial de instituições de ensino. Os participantes revestem-se de um espírito nobre de "ajuda à ciência" e se dispõe a ajudar com boa vontade admirável. Sentem-se verdadeiramente honrados com a participação. Neste contexto o pesquisador tem o papel de canalizar e filtrar esta energia, primeiramente para o bem do ser humano e em segundo lugar para o bem da ciência. Necessariamente nesta ordem.

Pesquisa com seres humanos não está restrita à área de ciências da saúde. As ciências sociais aplicada também detém a prerrogativa de investigar para adequar seus mecanismos de ação às demandas da sociedade e renovar o ensino. Normalmente nesta grande área haverá a predominância da pesquisa de análise documental, que, por pressupor acesso aos dados de pessoas estaria vinculada às mesmas normas éticas da pesquisa em seres humanos. Ressalta-se aqui o sigilo nos dados obtidos. Se na saúde expõe-se a vida, nas ciências sociais expõe-se a honra e eventualmente compromete-se a saúde, definida pela Organização Mundial de Saúde como "completo bem estar físico, mental e social e não somente ausência de enfermidades".

$\mathrm{Na}$ revisão da literatura internacional concluiu-se que a preocupação com danos decorridos pela experimentação científica é objeto de preocupação universal, assim como o repúdio às infrações. Entretanto, a percepção pessoal do pesquisador estaria na dependência de fatores pessoais e circunstanciais.

Observou-se, ao longo de história e mais acentuadamente após a segunda guerra mundial grande empenho nas normatizações da ética em pesquisa em seres humanos.

Desde a década 1980 ocorre no Brasil a construção da normatização da ética em pesquisa em seres humanos, fundamentadas em recomendações universais dos códigos internacionais que incorporam referenciais da bioética, autonomia, não maleficência, beneficência e justiça, dente outros que visam assegurar os direitos e deveres dos participantes de pesquisa em seres humanos. 
A referência ao Ministro César Peluso (2008) por ocasião da avaliação da constitucionalidade da lei de biossegurança "ciência é algo muito importante para ficar nas mãos dos cientistas" é adequada neste contexto, e parafraseando sua citação poderia ser dito que ciência é algo muito sério para ficar nas mãos de um colegiado político. É necessária ampla análise e discussão por bioeticistas, cientistas e juristas para eventuais modificações na regulação atual para que não haja retrocessos nos caminhos já percorridos.

\section{REFERÊNCIAS}

ALIGIERI, Paulo; TANNUS, Gabriel; LINS, Eleonora. Indústria farmacêutica: impacto na evolução da pesquisa clínica. Rev. Assoc. Med. Bras., São Paulo, v. 50, n. 4, p. 352, Dec. 2004 . Available from <http://www.scielo.br/scielo.php?script=sci_arttext\&pid=S0104 42302004000400007\&lng=en\&nrm=iso>. Access on 26 Mar. 2016. http://dx.doi.org/10.1590/S0104-42302004000400007.

ANDRADE, Fernando Cézar Bezerra; SILVA CORDEIRO, Filomena Maria Gonçalves. Ensino-pesquisa-extensão: um exercício de indissociabilidade na pós- graduação. Revista brasileira de educação, v. 14, n. 41, p. 269, 2009.

ARAÚJO, Laís Záu Serpa de. Aspectos éticos da pesquisa científica. Pesqui. odontol. bras, v. 17, n. supl. 1, p. 57-63, 2003.

AVELLEIRA JC, BOTTINO G. Súfilis: diagnóstico, tratamento e controle Syphilis: diagnosis, treatment and control. An Bras Dermatol. V. 81 n. 2, p. 111-26. 2006.

BEECHER, Henry K. Ethics and clinical research. New England journal of medicine, v. 274, n. 24, p. 1354-1360, 1966.

BRASIL. Ministério da Saúde. Conselho Nacional de Saúde. Resolução 466, 2012. BRASIL. Ministério da Saúde. Conselho Nacional de Saúde. Resolução 196, 1996.

BRASIL. Presidência da República. Casa Civil. Subchefia para Assuntos Jurídicos. Lei n. 11105. Março de 2005.

BRASIL. Supremo Tribunal Federal. Espaço do Servidor. Disponível em http://stf.jus.br/portal/cms/vernoticiadetalhe.asp?idconteudo=89917Acesso em

13/12/2015.SUSSMAN, Michael D. Ethical standards in the treatment of human subjects involved in clinical research. Journal of Pediatric Orthopaedics, v. 18, n. 6, p. 701-702, 1998.

CHILDRESS, James F. Nuremberg's legacy: some ethical reflections. Perspectives in Biology and Medicine, v. 43, n. 3, p. 347-361, 2000.

DEPARTMENT OF HEALTH, Education et al. The Belmont Report. Ethical principles and guidelines for the protection of human subjects of research. The Journal of the American College of Dentists, v. 81, n. 3, p. 4, 2014. 
DINIZ, Débora. Sob o escrútínio da ética. Disponível em http://alias.estadao.com.br/noticias/geral,sob-o-escrutinio-da-etica,181761. Acesso em 25/03/2016.

ECO, Umberto: entrevista [julho de 2015]. Entrevistadora: I Scamparini. Entrevista concedida ao programa Milênio, Globo News.

FESQUET José L. Albert Ludwig Neisser (1855-1916). Instituto de Historia de la Medicina y de la Ciencia (Universidad de Valencia-CSIC). Feb 2013 Disponível em http://www.historiadelamedicina.org/neisser.html, acesso em 20/02/2016.

GARIB ML. A boa fé objetiva aplicada à biotecnologia e o respeito aos princípios bioéticos. CONPEDI. Disponível em http://www.conpedi.org.br/publicacoes/c178h0tg/8v11nwv1/n6Wrf2szr67RQ38z.pdf Acesso em 20/02/2016.

GARRAFA, V; PRADO MM. Alterações na Declaração de Helsinque-a história continua. Revista Bioética, v. 15, n. 1, 2009.

GARRAFA, Volnei. Biotecnologia, ética e controle social. Cadernos de Ciência \& Tecnologia, v. 17, n. 2, p. 171-177, 2000.

GUILHEM Dirce, DINIZ Débora O que é ética em Pesquisa Editora Brasiliense, São Paulo, 2014.

HARKNESS J, LEDERER SE, WIKLER D. Laying ethical foundations for clinical research. Bulletin of the World Health Organization. v. 79 n.4 jan. 200. p. 365-6.

JUNQUEIRA CR. Bioética. Curso de Especialização em Saúde da Família-UNA-SUS UNIFESP. 2012 Mai p.28.

KATZ, Jay, "Human Sacrifice and Human Experimentation: Reflections at Nuremberg" (1996). Occasional Papers. Paper 5. Disponível em http://digitalcommons.law.yale.edu/ylsop_papers/5. Acesso em 28/02/2016.

LIGON, B. Lee. Albert Ludwig Sigesmund Neisser: discoverer of the cause of gonorrhea. In: Seminars in pediatric infectious diseases. WB Saunders, 2005. p. 336341.

MEZZAROBA, Orides; MONTEIRO, Cláudia Servilha. Manual de metodologia da pesquisa de direito. Saraiva. 2009.

MUNDIAL, Associação Médica. Declaração de Helsinque: princípios éticos para pesquisa ética envolvendo seres humanos. Disponível em http://iprexole.com/pdfs/Declaration_of_Helsinki_Portuguese.pdf. Acesso em 09/04/2016.

PALÁCIOS M, REGO S, SCHRAMM FR. A eticidade da pesquisa em seres humanos (CD-ROM) Pesquisas Especiais Barsa Society", versão 2.1, 2001.. 
PALÁCIOS, M.; REGO, S. A proposta de regulamentação ética da pesquisa clínica apresentada ao Senado Brasileiro não interessa aos participantes de pesquisa. Cad Saude Publica, v. 31, n. 8, p. 1583-5, 2015.

SARDENBERG, Trajano. A ética da pesquisa em seres humanos e a publicação de artigos científicos. Jornal de Pneumologia, v. 25, n. 2, p. 34, 1999.

SCHRAMM, Fermin Roland. Uma breve genealogia da bioética em companhia de Van Rensselaer Potter. Bioethikos, v. 5, n. 3, p. 302-8, 2011.

SEIDELMAN, W. E. The professional origins of Dr. Joseph Mengele. CMAJ: Canadian Medical Association Journal, v. 134, n. 8, p. 865, 1986.

SOLOMON M. The rhetoric of dehumanization: An analysis of medical reports of the Tuskegee syphilis project. Western journal of speech communication. V.30 n. 49. P. 233-47; dez 1985.

TAYLOR, T. Opening statement of the prosecution. In The Nazi Doctors and the Nuremberg Code: Human Rights in Human Experimentation, edited by G. J. Annas and M. A. Grodin. New York: Oxford Univ. Press, 1992. 70

TEN HAVE, Henk AMJ. Potter's notion of bioethics. Kennedy Institute of Ethics Journal, v. 22, n. 1, p. 59-82, 2012.

TENGAN C, VENANCIO PC, MARCONDES FK, ROSALEN PL. Autonomia e vulnerabilidade do sujeito da pesquisa. Revista de Direito Sanitário. V18; n 6 (1-3 ) p.

25-3. Out. 2005.VIEIRA, Sonia; HOSSNE, William Saad. Experimentação com seres humanos. Ciência \& Ensino, v. 2, n. 1, 2006.

WASHINGTON, HA. Bad medicine. New Scientist. 213, 2848, 24-25, Jan. 21, 2012. WHITE, Lawrence W. The Nazi doctors and the medical community; Honor or censure? The case of Hans Sewering. Journal of Medical Humanities, v. 17, n. 2, p. 119-135, 1996.

XII, Pope Pius. Moral Limits of Medical Research and Treatment: An Address Given. First International Congress on the Histopathology of the Nervous System.September 14, 1952 citado por BEECHER, Henry K. Ethics and clinical research. New England journal of medicine, v. 274, n. 24, p. 1354-1360, 1966.

ZANETTI, Carlo Henrique Goretti; TANNOUS, Gysélle Saddi. Sob a pele do PL-200/2015 do Senado Brasileiro. Epidemiologia e Serviços de Saúde, v. 24, n. 4, p. 789-794, 2015. 